\title{
Apolipoprotein C-III-1 Activates Lysosomal Sphingomyelinase In Vitro
}

\author{
Andrew J. Alpert and Arthur L. Beaudet, Departments of Pediatrics and Cell \\ Biology, Baylor College of Medicine, Houston, Texas 77030
}

A B S T R A C T Apolipoprotein (apo)C-III-1 from human very low density lipoprotein stimulates 14 -fold the activity of lysosomal sphingomyelinase from human fibroblasts. At the sphingomyelin concentrations tested, maximal stimulation was obtained with $5 \mu \mathrm{M}$ apoC-III-1 or apoC mixture. Apolipoproteins A-I, A-II, B, and C-I conferred little or no stimulation. Sphingomyelinase was stimulated 20-fold by lysophosphatidylcholine with an optimum concentration of $70 \mu \mathrm{M}$ using $0.3 \mathrm{mM}$ substrate. Sphingomyelinase activity was inhibited by concentrations of apoC-III-1 and lysophosphatidylcholine three- to fivefold above stimulatory levels. Triton X-100 activated sphingomyelinase 300 -fold with a $\mathrm{pH}$ optimum of 5.0 , while the $\mathrm{pH}$ optimum with the biological activators was 4.0. These results raise the possibility of an in vivo activity for the biological activators. The proteins that enter lysosomes as part of a lipoprotein complex may activate lysosomal enzymes that degrade the lipid components.

\section{INTRODUCTION}

Sphingomyelinase (sphingomyelin phosphorylcholine phosphohydrolase) (EC 3.1.4.12) hydrolyzes sphingomyelin to ceramide and phosphorylcholine. A lysosomal form of the enzyme requires no known cofactors (1-3). The lysosomal sphingomyelinase is absent or reduced in some forms of the hereditary disorder Niemann-Pick disease, resulting in excessive sphingomyelin storage in the tissues (4). Mammalian tissues also contain two forms of sphingomyelinase with

Received for publication 7 August 1981 and in revised form 5 October 1981. neutral $\mathrm{pH}$ optima. One requires divalent cations for activity $(3,5,6)$, while the other does not (7).

Some sphingolipid hydrolases lose activity toward their natural substrates upon purification. Activity can be restored by small glycoproteins from lysosomes or from heated extracts of tissues $(8-11)$. These small proteins have been referred to as activators and may combine with sphingolipids to form complexes (12), which are more suitable substrates for the sphingolipid hydrolases. There is evidence that these activator proteins may facilitate the hydrolysis of sphingolipids in vivo (8). In the case of sphingomyelinase, effects of activator proteins have been reported $(9,11)$. In many instances, sphingolipid hydrolase activity can be promoted by a detergent in the absence of an activator protein. Triton X-100 is widely used for demonstration of sphingomyelinase activity. This detergent forms a mixed micelle with sphingomyelin (13).

Sphingomyelin is an important constituent of membranes. It is transported through the blood as an integral component of lipoproteins (14) that can be taken up by the cells in various tissues. Koenig (15) found that a large partion of lysosomal protein consists of lipoproteins. These studies examine the interaction of various plasma apolipoproteins with lysosomal sphingomyelinase. The in vitro results raise the possibility that apolipoprotein C-III-1 (apoC-III-1) ${ }^{1}$ may function as an activator of lysosomal sphingomyelinase in vivo. The effect of the abundant phospholipid, phosphatidylcholine, was also examined. In addition, the effect of the natural detergent lysophosphatidylcholine (LPC)

${ }^{1}$ Abbreviations used in this paper: apoA-I, A-II, B, C, C-I, C-II, and C-III, apolipoproteins A-I, A-II, B, C, C-I, C-II, and C-III; LPC, lysophosphatidylcholine. 
was studied, since it might be produced in the lysosome as a product of lipoprotein metabolism.

\section{METHODS}

[Choline-methyl $-{ }^{14} \mathrm{C}$ ] sphingomyelin was purchased from New England Nuclear, Boston, Mass. Unlabelled sphingomyelin was obtained from Koch-Light Laboratories, Ltd., Colnbrook, Buckinghamshire, England. LPC (lysolecithin type I), phosphatidylcholine (type V-E), and Triton X-100 were purchased from Sigma Chemical Co., St. Louis, Mo.

The apolipoproteins were kindly supplied by the following researchers in the Division of Atherosclerosis and Lipoprotein Research, Baylor College of Medicine, Houston, Tex.: apoA-I, apoA-II, and apoC mixture (very low density lipoproteins) from T. C. Chen; apoC-I and apoC-III-1 from H. J. Pownall; apoC-II from J. D. Morrisett; apoB from M. F. Rohde. ApoA-I (16), A-II (16), B (17), and the C group (18) were prepared with published methods. ApoA-I was in $50 \mathrm{mM}$ borate, $\mathrm{pH}$ 8.0. The other apolipoproteins were in $100 \mathrm{mM}$ $\mathrm{NaCl}, 10 \mathrm{mM}$ Tris-Cl, $1 \mathrm{mM}$ EDTA, $1 \mathrm{mM} \mathrm{NaN}$, pH 7.4 (buffer A). In addition, the apoC-III-1 solution contained $0.5 \mathrm{M}$ guanidinium hydrochloride. These variations in salts and buffers were determined to have minimal effect on sphingomyelinase activity under the conditions used. Apolipoprotein solutions were diluted as needed into buffer A immediately before use. The components of the apoC mixture were assumed to have an average molecular weight of 8700 .

A $2 \mathrm{mM}$ phosphatidylcholine suspension was prepared in water as described below for sphingomyelin.

Preparation of extracts. Human skin fibroblasts were cultured as described previously (19). $10 \mathrm{~d}$ after cells achieved confluence they were washed three times with $0.9 \%$ saline, and the cells from a $150-\mathrm{mm}$ plate were scraped in $0.8 \mathrm{ml}$ of deionized water. The cells were disrupted by sonication for two intervals of $15 \mathrm{~s}$ using a Branson sonifier (Branson Sonic Power Co., Danbury, Conn.) set to an output of $30 \mathrm{~W}$. The mixture was centrifuged at $1,000 \mathrm{~g}$ for $10 \mathrm{~min}$ and the supernatant (1.3-1.7 mg protein/ml) used for enzyme assay.

Enzyme assays. Protein was measured according to Lowry et al. (20), using bovine serum albumin as standard.

Radioactive sphingomyelin was mixed with unlabeled sphingomyelin in toluene: methanol $1: 1$ to give a $6 \mathrm{mM}$ stock solution with a $0.87 \mathrm{mCi} / \mathrm{mmol} \mathrm{sp}$ act. For the preparation of substrate solution, the solvent was evaporated from an aliquot of stock solution with a stream of $\mathrm{N}_{2}$. The substrate was suspended in $0.2 \mathrm{M}$ sodium acetate to give a concentration of $0.6 \mathrm{mM}$ and the mixture heated at $50^{\circ} \mathrm{C}$ for $3 \mathrm{~min}$, with vigorous vortex mixing. The assay reaction volume was $0.1 \mathrm{ml}$ with the following final concentrations: $0.1 \mathrm{M}$ sodium acetate (pH 4.0 or as indicated) and $0.30 \mathrm{mM}$ (or less as noted) $\left[{ }^{14} \mathrm{C}\right]$ sphingomyelin. Reactions were started by the addition of $10 \mu \mathrm{l}$ of fibroblast extract. Samples were mixed vigorously at this time and again after $3-\mathrm{h}$ incubation at $37^{\circ} \mathrm{C}$. The time of incubation was $6 \mathrm{~h}$ unless indicated otherwise; the rate was linear up to $24 \mathrm{~h}$. Reactions were stopped by the sequential addition of $1.0 \mathrm{ml}$ cold $1 \%$ bovine serum albumin solution, $0.3 \mathrm{ml}$ of $50 \% \mathrm{TCA}$, and $0.1 \mathrm{ml}$ of cold $10 \%$ bovine serum albumin solution. The mixture was centrifuged $10 \mathrm{~min}$ at $1000 \mathrm{~g} .1 \mathrm{ml}$ of the supernatant was added to $9.0 \mathrm{ml}$ Aquasol (New England Nuclear) and the released $\left[{ }^{14} \mathrm{C}\right]$ phosphorylcholine was quantitated in a Beckman LS-3133T Scintillation Counter (Beckman Instruments, Fullerton, Calif.).

\section{RESULTS}

Fig. 1 shows the effect of apolipoproteins, LPC, and Triton X-100 on sphingomyelinase activity. LPC at

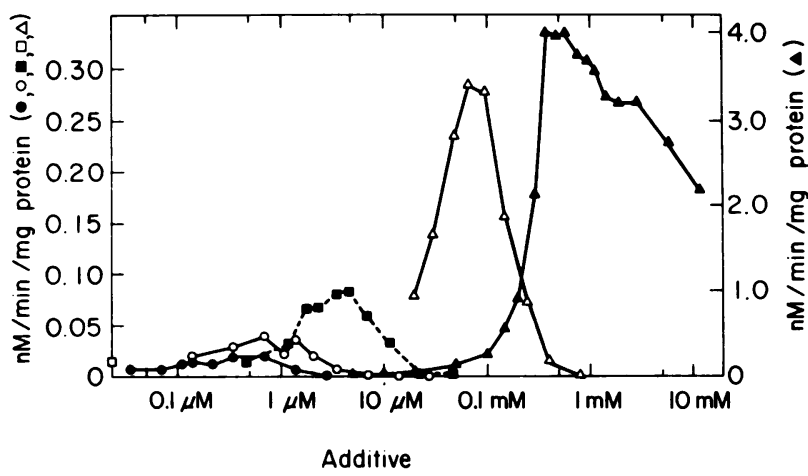

FIGURE 1 Effect of apolipoproteins, LPC, and Triton X-100 on lysosomal sphingomyelinase activity. Assays were conducted as described in Methods, using $3.9 \mu \mathrm{g}$ of extract protein with Triton X-100 or $13 \mu \mathrm{g}$ with all other additives. The additives present were: $\square$, none; $\bigcirc$, apoA-I; $O$, apoA-II; $\boldsymbol{\square}$, apoC mixture; $\triangle$, LPC; $\Delta$, Triton X-100.

$70 \mu \mathrm{M}$ stimulated the reaction 20 -fold. An apoC mixture stimulated activity sixfold at a concentration of $4.5 \mu \mathrm{M}$. ApoA-I and apoA-II conferred very little stimulation. The reaction rate was minimal when apoC mixture or LPC was present in a concentration 10 times greater than that optimal for activation. Although not shown, apoB did not stimulate sphingomyelinase activity over a concentration range of $1.15-92 \mu \mathrm{g} / \mathrm{ml}$, and inhibited the reaction when present in high concentration. No stimulation was observed when phosphatidylcholine was present in a concentration range of $2 \mu \mathrm{M}$ to $0.8 \mathrm{mM}$. Triton X-100 stimulated sphingomyelinase activity 300 -fold. The optimal concentration for Triton $\mathrm{X}-100$ was $0.5 \mathrm{mM}$ with a sphingomyelin to Triton $\mathrm{X}-100$ molar ratio of 0.6 , thus re quiring a much higher concentration than for the natural additives. The reaction rate was still $70 \%$ of the maximum when the concentration of Triton X-100 was 10 times greater than the optimal concentration.

Fig. 2 shows the effects of individual components of the apoC mixture on sphingomyelinase activity. The optimum concentration for stimulation by apoC-III-1 was $5 \mu \mathrm{M}$, which was in the same range as for the apoC mixture. ApoC-III-1 was more effective, with a 14-fold stimulation observed. ApoC-I was a poor stimulator and was an inhibitor at high concentration. ApoC-II conferred modest stimulation, and then only when present at high concentration. The reaction rate was minimal when apoC-III-l was present at 10 times the optimal concentration.

The $\mathrm{pH}$ optimum of sphingomyelinase was 4.0 when stimulated by apoA-II, apoC-III-1, or LPC (Fig. 3). The reaction had a $\mathrm{pH}$ optimum of 5.0 when stimulated by Triton X-100. No activation was observed with the apolipoprotein or LPC additions when extract from 


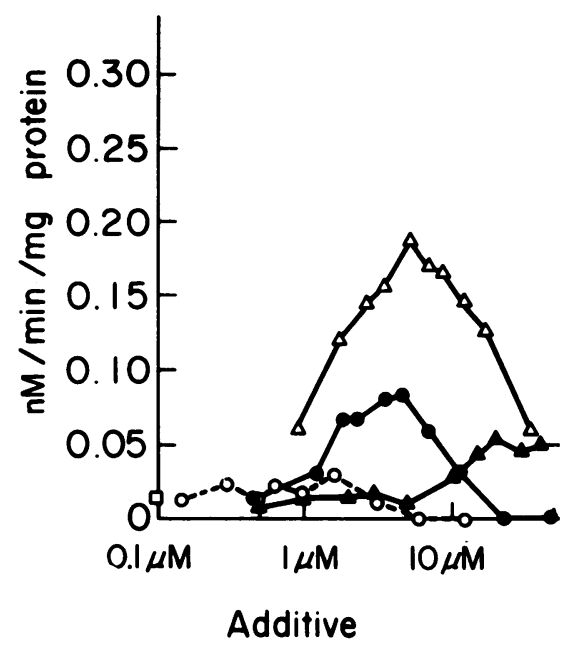

FIGURE 2 Effect of apoC on lysosomal sphingomyelinase activity. Assays were conducted as described in Methods, using $13 \mu \mathrm{g}$ of extract protein. The additives present were: $\square$, none;, apoC mixture; $\bigcirc$, apoC-I; $\Delta$, apoC-II; $\Delta$, apoC-III-1.

sphingomyelinase-deficient fibroblasts was used. This result, with the $\mathrm{pH}$ optimum data, indicated that the lysosomal sphingomyelinase was the activated enzyme.

The concentration of LPC that conferred maximal activation was dependent on the concentration of the substrate (Fig. 4). A 10-fold decrease in the concentration of sphingomyelin produced a twofold decrease in

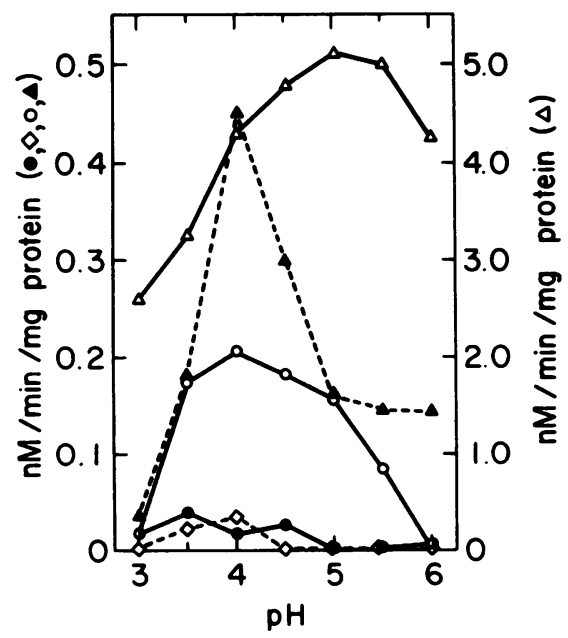

FIGURE 3 Activation of lysosomal sphingomyelinase by various additives as a function of $\mathrm{pH}$. Assays were conducted as described in Methods, using $3.9 \mu \mathrm{g}$ of extract protein with Triton X-100, $13 \mu \mathrm{g}$ with apoA-II, or $16 \mu \mathrm{g}$ with LPC and apoC-III- 1 . The additives present were: $\bullet$, none; $\diamond$, apoA-II; O, apoC-III-1; $\Delta$, LPC; $\triangle$, Triton X-100.

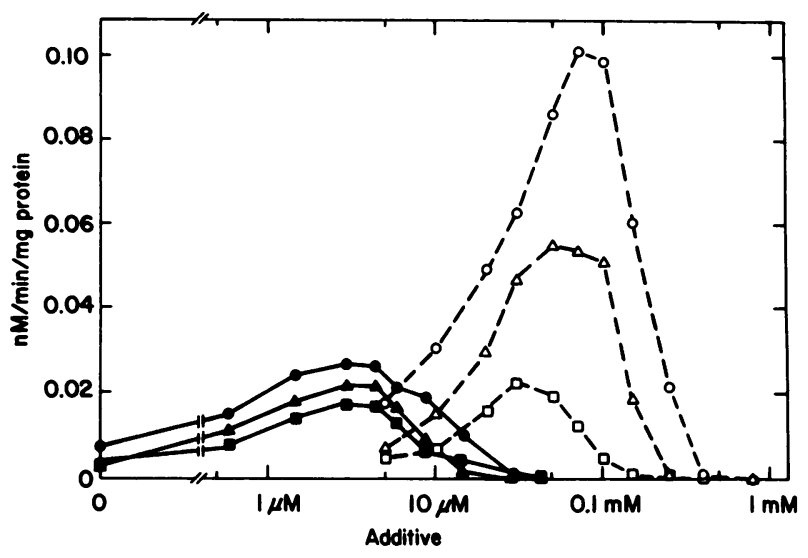

FIGURE 4 Effect of sphingomyelin concentration on the activation of lysosomal sphingomyelinase by apoC mixture and LPC. Assays were conducted as described in Methods, using $12 \mu \mathrm{g}$ of extract protein. The incubation times were $16 \mathrm{~h}$ for LPC and $18 \mathrm{~h}$ for apoC mixture. ApoC mixture was added to all assay samples in $15 \mu \mathrm{l}$ buffer $\mathrm{A}$. The additives present were: $\bullet, \Delta, \boldsymbol{\square}$, apoC mixture; $\bigcirc, \triangle, \square$, LPC; $, \bigcirc, 300 \mu \mathrm{M}$ sphingomyelin; $\Delta, \Delta, 120 \mu \mathrm{M}$ sphingomyelin; $\mathbf{\square}, \square, 30 \mu \mathrm{M}$ sphingomyelin.

the optimal concentration of LPC. By contrast, the optimal concentration of apoC mix was independent of sphingomyelin concentration over this range.

\section{DISCUSSION}

We have observed a clear activation of lysosomal sphingomyelinase by apoC-III-1 in vitro. It remains to be determined whether or not this is a significant phenomenon in the intact organism. Up to the present, attention has focused on the role of apolipoproteins in the extracellular space. ApoA-I and apoC-I activate lecithin-cholesterol acyltransferase (21). ApoC-II activates lipoprotein lipase, and this activation is antagonized by apoA-I, A-II, C-I, C-III, E, and excess C-II $(22,23)$. Lipoproteins are taken up by cells, and apoE enhances uptake while apoC-III-1 antagonizes this effect $(24,25)$. Low density lipoproteins, taken into the cell, enter the lysosome specifically (26). It is possible that apolipoproteins entering cells have specific intracellular functions, such as activation of lysosomal hydrolases.

The term activator has been used to describe certain proteins that promote an enzymatic process involving lipid substrates. Activators for lysosomal sphingolipid hydrolases, for lecithin-cholesterol acyl transferase, and for lipoprotein lipase are examples. In some instances, detergents can substitute for these activators in vitro, and their role may be simply to promote interaction of substrate with enzyme. In other instances, a more direct regulator role for the activator is possible. Activator proteins may interact with substrate or with 
enzyme or possibly with both components $(27,28)$. We have not performed direct studies to assess interaction of apoC-III-1 with sphingomyelin or sphingomyelinase. However, the data in Fig. 4 provide some indirect evidence that apoC-III-1 does not exert its effect solely by forming a complex with substrate, since the optimum concentration of apoC-III-1 might be expected to vary with sphingomyelin concentration in that instance. By comparison, the concentration of LPC optimal for activation of sphingomyelinase did vary with substrate concentration, suggesting the formation of a substrate complex. LPC can form either vesicles or mixed micelles with phospholipids under various conditions (29).

The question remains whether or not the activation of sphingomyelinase by apoC-III-1 is physiologically significant. The occurrence of the $A B$ variant of $G_{2}$ gangliosidosis due to deficiency of an activator protein (8) argues strongly that some in vitro activators are important in the organism, as does the occurrence of hypertriglyceridemia due to apoC-II deficiency and the consequent effect on lipoprotein lipase (30). The fact that apoC-III-1 activates sphingomyelinase, while other apolipoproteins do not, might favor a functional significance for the activity. These observations raise the possibility that lysosomal activators might not simply arise endogenously in the cell, but also could originate outside the cell in the process of metabolic turnover. Plasma apolipoproteins would form one such class of activators. Another might be proteins that form complexes with lipids in the brain. Such activator proteins could play a role in targeting lipoprotein complexes to the lysosome and/or in the activation of lysosomal hydrolases. Finally, our observations raise the possibility that some forms of sphingomyelin lipidosis that exhibit normal sphingomyelinase activity in vitro might be due to abnormalities in an activator protein such as apoC-III.

\section{ACKNOWLEDGMENT}

This work was supported by grant GM-25397 from the U.S. Public Health Service. The authors were members of the Howard Hughes Medical Institute during part of this work.

\section{REFERENCES}

1. Kanfer, J. N., O. M. Young, D. Shapiro, and R. O. Brady. 1966. Metabolism of sphingomyelin. I. Purification and properties of a sphingomyelin-cleaving enzyme from rat liver tissue. J. Biol. Chem. 241: 1081-1084.

2. Yamaguchi, S., and K. Suzuki. 1977. Purification and characterization of sphingomyelinase from human brain. J. Biol. Chem. 252: 3805-3813.

3. Hostetler, K. Y., and P. J. Yazaki. 1979. The subcellular localization of neutral sphingomyelinase in rat liver. J. Lipid Res. 20: 456-463.
4. Brady, R. O. 1978. Sphingomyelin lipidosis: NiemannPick disease. In The Metabolic Basis of Inherited Disease. J. B. Stanbury, J. B. Wyngaarden, and D. S. Fredrickson, editors. McGraw-Hill Book Co., Inc., New York. 4th edition. 718-730.

5. Rao, B. G., and M. W. Spence. 1976. Sphingomyelinase activity at $\mathrm{pH} 7.4$ in human brain and a comparison to activity at $\mathrm{pH}$ 5.0. J. Lipid Res. 17: 506-515.

6. Gatt, S. 1976. Magnesium-dependent sphingomyelinase. Biochem. Biophys. Res. Commun. 68: 235-241.

7. Yamaguchi, S., and K. Suzuki. 1978. A novel magnesiumindependent neutral sphingomyelinase associated with rat central nervous system myelin. J. Biol. Chem. 253: 4090-4092.

8. Conzelmann, E., and K. Sandhoff. 1978. AB variant of infantile $\mathrm{G}_{\mathrm{M} 2}$ gangliosidosis: deficiency of a factor necessary for stimulation of hexosaminidase A-catalyzed degradation of ganglioside $\mathrm{G}_{\mathrm{M} 2}$ and glycolipid $\mathrm{G}_{\mathrm{A} 2}$. Proc. Natl. Acad. Sci. U.S.A. 75: 3979-3983.

9. Mraz, W., G. Fischer, and H. Jatzkewitz. 1976. Low molecular weight proteins in secondary lysosomes as activators of different sphingolipid hydrolases. FEBS (Fed. Eur. Biochem. Soc.) Lett. 67: 104-109.

10. Li, S.-C., and Y.-T. Li. 1976. An activator stimulating the enzymic hydrolysis of sphingoglycolipids. J. Biol. Chem. 251: 1159-1163.

11. Baraton, G., and A. Revol. 1977. Activateur des sphingohydrolases et nature du deficit en sphingomyelinase dans la maladie de Niemann-Pick type A, B et C. Clin. Chim. Acta. 76: 339-343.

12. Fischer, G., and H. Jatzkewitz. 1977. The activator of cerebroside sulphatase. Binding studies with enzyme and substrate demonstrating the detergent function of the activator protein. Biochim. Biophys. Acta. 481: 561-572.

13. Gatt, S., T. Dinur, S. Yedgar, and Z. Leibovitz-Ben Gershon. 1978. Effect of detergents on the utilization of sphingomyelin by brain sphingomyelinases. Adv. Exp. Med. Biol. 101 (Enzymes of Lipid Metabolism): 487-500.

14. Skipski, V. P. 1972. Lipid composition of lipoproteins in normal and diseased states. In Blood Lipids and Lipoproteins: Quantitation, Composition and Metabolism. G. J. Nelson, editor. Wiley-Interscience Div., New York. 471-583.

15. Koenig, H. 1969. Lysosomes in the nervous system. In Frontiers of Biology: Lysosomes in Biology and Pathology. J. T. Dingle, and H. B. Fell, editors. North-Holland Publishing Company, Amsterdam-London. 2: 111-162.

16. Scanu, A., J. Toth, C. Edelstein, S. Koga, and E. Stiller. 1969. Fractionation of human serum high density lipoprotein in urea solutions. Evidence for polypeptide heterogeneity. Biochemistry. 8: 3309-3316.

17. Socorro, L., and G. Camejo. 1979. Preparation and properties of soluble, immunoreactive apoLDL. J. Lipid Res. 20: 631-638.

18. Brown, W. V., R. I. Levy, and D. S. Fredrickson. 1969. Studies of the proteins in human plasma very low density lipoproteins. J. Biol. Chem. 244: 5687-5694.

19. Beaudet, A. L., M. H. Lipson, G. D. Ferry, and B. L. Nichols, Jr. 1974. Acid lipase in cultured fibroblasts: cholesterol ester storage disease. J. Lab. Clin. Med. 84: 54-61.

20. Lowry, O. H., N. J. Rosebrough, A. L. Farr, and R. J. Randall. 1951. Protein measurement with the Folin phenol reagent. J. Biol. Chem. 193: 265-275.

21. Soutar, A. K., C. W. Garner, H. N. Baker, J. T. Sparrow, R. L. Jackson, A. M. Gotto, and L. C. Smith. 1975. Effect of the human plasma lipoproteins and phosphatidylcholine 
acyl donor on the activity of lecithin:cholesterol acyltransferase. Biochemistry. 14: 3057-3064.

22. Krauss, R. M., P. N. Herbert, R. I. Levy, and D. S. Fredrickson. 1973. Further observations on the activation and inhibition of lipoprotein lipase by apolipoproteins. Circ. Res. 33: 403-411.

23. Ekman, R., and P. Nilsson-Ehle. 1975. Effects of apolipoproteins on lipoprotein lipase activity of human adipose tissue. Clin. Chim. Acta. 63: 29-35.

24. Innerarity, T. L., and R. W. Mahley. 1978. Enhanced binding by cultured human fibroblasts of apo-E-containing lipoproteins as compared with low density lipoproteins. Biochemistry. 17: 1440-1447.

25. Shelburne, F., J. Hanks, W. Meyers, and S. Quarfordt 1980. Effect of apoproteins on hepatic uptake of triglyceride emulsions in the rat. J. Clin. Invest. 65: 652-658.
26. Brown, M. S., S. E. Dana, and J. L. Goldstein. 1975. Receptor-dependent hydrolysis of cholesteryl esters contained in plasma low density lipoprotein. Proc. Natl. Acad. Sci. U.S.A. 72: 2925-2929.

27. Ho, M. W., and M. Rigby. 1975. Glucocerebrosidase: stoichiometry of association between effector and catalytic proteins. Biochim. Biophys. Acta. 397: 267-273.

28. Hechtman, P., and D. LeBlanc. 1977. Purification and properties of the hexosaminidase A-activating protein from human liver. Biochem. J. 167: 693-701.

29. Morris, D. A. N., R. McNeil, F. J. Castellino, and J. K. Thomas. 1980. Interaction of lysophosphatidylcholine with phosphatidylcholine bilayers. A photo-physical and NMR study. Biochim. Biophys. Acta. 599: 380-390.

30. Breckenridge, W. C., J. A. Little, G. Steiner, A. Chow, and M. Poapst. 1978. Hypertriglyceridemia associated with deficiency of apolipoprotein C-II. N. Engl. J. Med. 298: $1265-1273$. 